\title{
Novos Onciderini (Coleoptera, Cerambycidae) da Bolívia
}

\author{
Ubirajara R. Martins ${ }^{1,3}$ \& Maria Helena M. Galileo ${ }^{2,3}$
}

${ }^{1}$ Museu de Zoologia, Universidade de São Paulo. Caixa Postal 42494, 04218-970 São Paulo-SP, Brasil.

${ }^{2}$ Museu de Ciências Naturais, Fundação Zoobotânica do Rio Grande do Sul. Caixa Postal 1188, 90001-970 Porto Alegre-RS, Brasil.

${ }^{3}$ Bolsista do CNPq.

\begin{abstract}
New Onciderini (Coleoptera, Cerambycidae) from Bolívia. New species described from Santa Cruz, Buena Vista (Flora \& Fauna Hotel): Trestoncideres albiventris sp. nov., Trestonia morrisi sp. nov. and Oncideres wappesi sp. nov.
\end{abstract}

KEYWORDS. Bolivia; Cerambycidae; Coleoptera; Lamiinae, Onciderini.

RESUMO. Novos Onciderini (Coleoptera, Cerambycidae) da Bolívia. Novas espécies de Onciderini são descritas da Bolívia, Santa Cruz, Buena Vista (Hotel Flora \& Fauna): Trestoncideres albiventris sp. nov., Trestonia morrisi sp. nov. e Oncideres wappesi sp. nov.

PALAVRAS-CHAVE. Bolívia; Cerambycidae; Coleoptera; Lamiinae, Onciderini.

Baseados em material enviado para estudo por James Wappes, descrevemos três espécies da tribo Onciderini que foi objeto de revisão por Dillon \& Dillon $(1945,1946)$. Após essa revisão muitos trabalhos foram publicados sobre essa tribo que necessita de outra revisão para ampliar aquela de Dillon \& Dillon.

James Wappes, do American Coleoptera Museum, Bulverde (ACMB) está reunindo e nos enviando para estudo material de diversas coleções e instituições, uma delas a Coleção Morris (CRML); determinou que os holótipos das espécies descritas da Bolívia sejam depositados no Museu Noel Kempf Mercado, Santa Cruz, Santa Cruz, Bolívia (MNKM). Alguns exemplares ficam retidos para o Museu de Zoologia, Universidade de São Paulo, São Paulo (MZSP) e para o Museu de Ciências Naturais, Fundação Zoobotânica do Rio Grande do Sul, Porto Alegre (MCNZ).

\section{Trestoncideres albiventris sp. nov.}

$$
\text { (Fig. } 1 \text { ) }
$$

Etimologia. Latim, albo = branco; ventris $=$ ventre, referente ao colorido da face ventral do corpo.

Cabeça com tegumento acastanhado. Fronte com pubescência predominantemente alaranjada. Pubescência castanho-escura: anel no topo dos tubérculos anteníferos; mancha longitudinal, central nos lados da sutura coronal; manchas atrás dos lobos oculares superiores. Fronte quadrangular com carena fina e contígua aos lobos oculares inferiores. Lobos oculares superiores com seis fileiras de omatídios, mais afastados entre si do que o dobro da largura de um lobo. Antenas com tegumento avermelhado, escurecido na clava do escapo e no ápice dos flagelômeros III a X. Lado interno da base do escapo, nos machos, profundamente sulcado; nas fêmeas, sem sulco.
Pronoto com pubescência alaranjada e uma faixa larga, acastanhada, longitudinal, de cada lado da base ao ápice. Disco pronotal com uma área glabra centro-basal.

Élitros com área sutural alaranjada, da base ao terço apical; lados e terço apical com pubescência amarelada; numerosos grânulos brilhantes no quarto basal e sobre a parte alaranjada; fileira de grânulos que se inicia nos úmeros e se estende até o quinto basal dos élitros; restante da área pontuada com pubescência alaranjada. Mesepimero, mesepisterno, metepisterno com pubescência castanha; restante da face ventral com pubescência branca, muito concentrada nos lados do metasterno.

Fêmures com tegumento preto; avermelhado na face dorsal e cobertos por pubescência amarelada. Tíbias e tarsos com tegumento avermelhado e pubescência amarelada.

Dimensões, mm, respectivamente macho/fêmea. Comprimento total, 14,3/12,3; comprimento do protórax, 2,1/ 2,0; largura anterior do protórax, 3,5/3,4; largura na base do protórax, 3,3/3,2 comprimento do élitro, 9,2/9,3; largura umeral, $4,5 / 4,4$.

Material-tipo. Holótipo macho, BOLÍVIA, Santa Cruz: Buena Vista (Hotel Flora \& Fauna, 4-6 km SSE), 1-15.I.2003, R. Clarke col. (MNKM). Parátipos: BOLÍVIA, Santa Cruz: Buena Vista (Hotel Flora \& Fauna, 4-6 km SSE), fêmea, 15-28.II.2003, R. Clarke col. (MZSP); fêmea, 17-30.IV.2003, R. Clake col. (ACMB, MZSP); fêmea, 1417.XI.2003, Morris, Nearns \& Wappes col. (CRML); fêmea, 2125.XI.2003, Morris, Nearns \& Wappes col. (MCNZ); fêmea, 2-9.I.2004, R. Clarke col. (ACMB); Buena Vista (5 km W, El Cairo), macho, 2629.IV.2004, Wappes \& Cline col. (MZSP).

Discussão. Trestoncideres albiventris sp. nov. distinguese de T. laterialba Martins \& Galileo, 1990, pelo padrão de colorido dos élitros com área sutural na metade anterior alaranjada, distintamente separada das áreas laterais e apical de pubescência amarelada; pelos grânulos elitrais maiores e os pontos dorsais evidentes e, principalmente, pela face ventral 
revestida por pubescência branca. Em T. laterialba (Fig. 4) a pubescência apical é uniformemente laranja-esbranquiçada; os grânulos elitrais na base são menores e os pontos dorsais estão ausentes; a face ventral tem apenas os lados do metasterno com pubescência branca.

\section{Trestonia morrisi sp. nov.}

(Fig. 2)

Etimologia. Epíteto em homenagem a Roy F. Morris, um dos coletores do holótipo.

Fronte revestida por densa pubescência branca menos junto ao clípeo, com mácula semilunar de pubescência alaranjada e acastanhada no centro; uma outra mancha no início da sutura coronal, preta no centro e alaranjada aos lados. Vértice com pubescência esbranquiçada até entre os lobos oculares superiores; mancha preta transversal adiante do occipício; partes laterais da cabeça coberta por pubescência predominantemente acastanhada. Antenas com tegumento avermelhado, flagelômeros com estreito anel apical escurecido; atingem o ápice dos élitros na ponta do antenômero VI.

Protórax com tegumento acastanhado, revestido por pubescência variegada de amarelada e acastanhada; partes laterais do protórax com mais pubescência esbranquiçada.

Élitros com pequena área circum-escutelar preta, pubescência esbranquiçada da base segue obliquamente do úmero em direção à sutura no sexto anterior, vai pela sutura até o meio onde termina numa faixa larga situada atrás do meio e na parte anterior da faixa preta antiapical. Restante da superfície elitral coberta por pubescência mesclada de alaranjada e esbranquiçada. Úmeros salientes seguidos de curta carena voltada para o lado interno. Terço apical dos élitros com duas pequenas manchas dorsais pretas; região apical com tegumento preto, coberto por áreas irregulares de pubescência alaranjada e branca.

Meso- e metafêmures com pubescência predominantemente rósea. Esternos torácicos com pubescência variegada de branco e alaranjado. Urosternito I com grande mancha lateral preta; demais urosternitos com pubescência esbranquiçada.

Dimensões, mm, respectivamente macho/fêmea. Comprimento total, 13,1/14,0; comprimento do protórax, 2,2/ 2,4; maior largura do protórax, 3,4/3,1; comprimento do élitro, 9,0/10,2; largura umeral, 4,3/4,8.

Material-tipo. Holótipo macho, BOLÍVIA, Santa Cruz: Buena Vista (Hotel Flora \& Fauna), 21-25.XI.2003, Morris, Nearns \& Wappes col. (MNKM). PANAMÁ, Ilha de Barro Colorado, parátipo fêmea, 19.V.1964, W. D. \& S. S. Duckworth col. (MZSP).

Discussão. Trestonia morrisi sp. nov. assemelha-se a $T$. forticornis Buquet, 1859, mas difere, principalmente, pelos tubérculos anteníferos sem cornos (nos machos); pelas antenas muito mais longas; pelos lados do protórax sem pequeno tubérculo; pelo padrão de colorido dos élitros com mancha circum-escutelar e área de pubescência branca basal; pela mácula do ápice dos élitros preta entremeada interiormente por pilosidade alaranjada e branca; pela presença de mancha preta nos lados do urosternito I. Em T. forticornis (Fig. 5), os tubérculos anteníferos são projetados em corno; as antenas atingem o ápice dos élitros na ponta do antenômero VIII; os lados do protórax têm tubérculo; os élitros não têm mancha circum-escutelar nem pubescência branca junto à base; a mácula apical preta dos élitros não é entremeada por pubescência colorida; os lados do urosternito I não têm mancha preta.

\section{Oncideres wappesi sp. nov.}

(Fig. 3)

Etimologia. Nome específico em homenagem a James Wappes (ACMB) pelo envio de material para estudo.

Cabeça com tegumento preto; pubescência laranjaamarelada, mais concentrada ao redor dos lobos inferiores dos olhos. Lobos oculares inferiores com o triplo do comprimento das genas. Antenas (macho) atingem a extremidade dos élitros na base do antenômero VII. Escapo com tegumento preto. Pedicelo e flagelômeros com tegumento avermelhado.

Protórax com tegumento castanho, revestido por pubescência amarelada; pubescência alaranjada numa área transversal à frente dos cinco tubérculos glabros. Lados do protórax com pequeno tubérculo glabro e brilhante.

Élitros com tegumento avermelhado, com tubérculos grandes, pretos, pouco numerosos no quinto basal; um tubérculo glabro envolve os úmeros; superfície dos élitros coberta por pubescência amarelo-alaranjada e salpicada por inúmeras manchas arredondadas de pubescência branca entremeadas por pincéis menores, abundantes, também de pubescência branca.

Fêmures com tegumento acastanhado revestidos por pubescência amarelo-alaranjada.

Lado inferior do corpo com pubescência predominantemente esbranquiçada; pubescência dos lados do metasterno, nos machos, entremeada por pubescência alaranjada, que chega a ser a cor predominante. Nas fêmeas, a pilosidade esbranquiçada tem escassa pubescência alaranjada entremeada.

Dimensões, mm, respectivamente macho/fêmea. Comprimento total, 11,0/14,5-16,7; comprimento do protórax, 2,0/2,2-2,4; maior largura do protórax, 2,7/4,1-4,5; comprimento do élitro, 8,2/10,9-11,1; largura umeral, 3,9/5,3-5,7; comprimento do lobo ocular inferior, 1,4/1,5-1,6; comprimento da gena, $0,5 /$ $0,8-1,0$.

Material-tipo. Holótipo macho, BOLÍVIA, Santa Cruz: Buena Vista (Hotel Flora \& Fauna, 3,7 km SSE, $430 \mathrm{~m}$ ), 15-22.XI.2001, B. K. Dozier col. "black light trap, trasition forest" (MNKM). Parátipo macho, BOLÍVIA, Santa Cruz: Buena Vista (Hotel Flora \& Fauna, 4-6 km SSE), fêmea, 27-29.X.2000, Wappes \& Morris col. (ACMB); fêmea,15-30.I.2004, R. Clarke col. (ACMB); fêmea, 1.II.2004, E. Ortez col. (MZSP).

Discussão. Oncideres wappesi sp. nov. assemelha-se a $O$. 

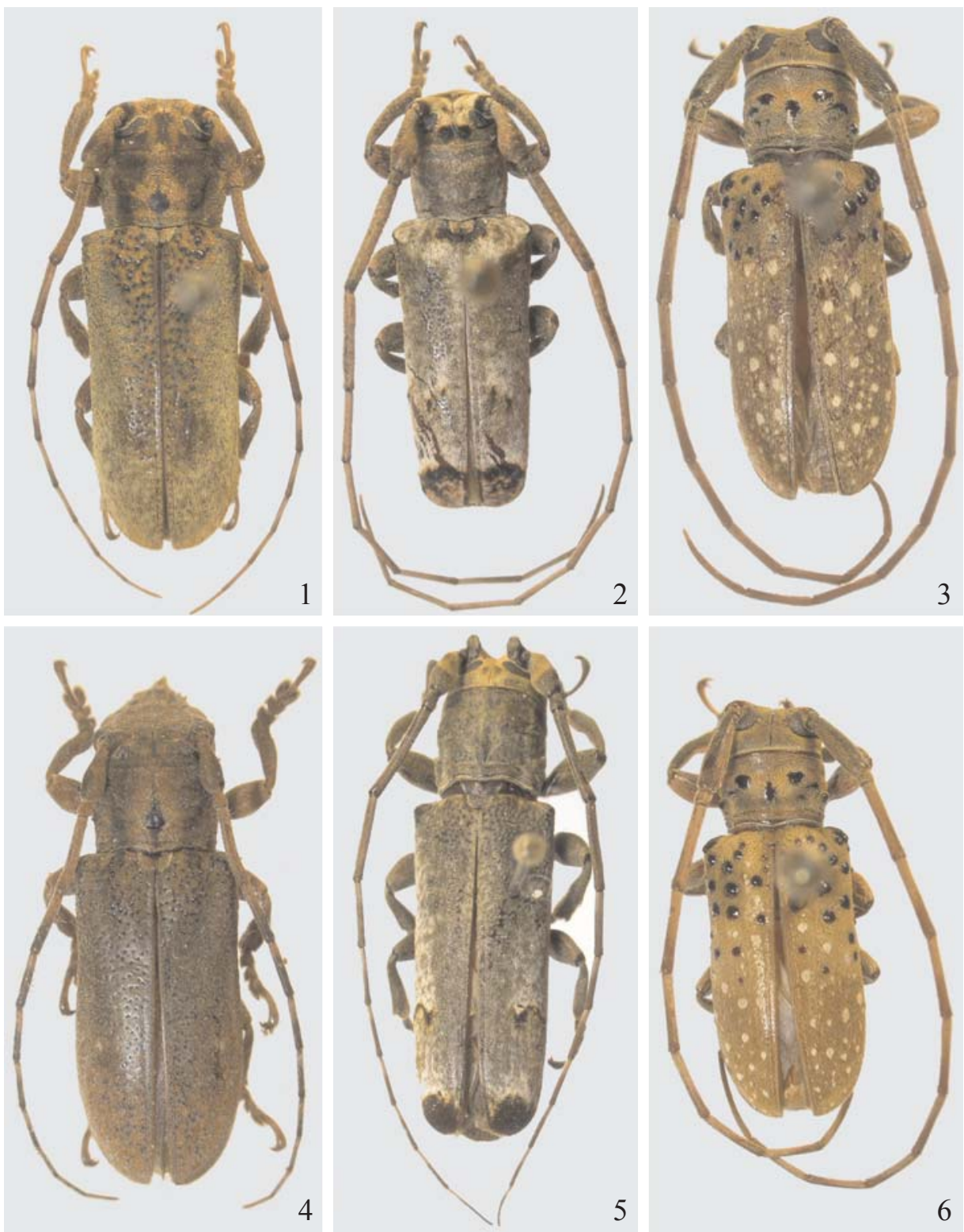

Figs. 1-6. 1, Trestoncideres albiventris sp. nov., parátipo fêmea, comprimento $12,3 \mathrm{~mm}$; 2, Trestonia morrisi sp. nov., holótipo macho, comprimento 13,1 mm; 3, Oncideres wappesi sp. nov., holótipo macho, comprimento 11,0 mm; 4, Trestoncideres laterialba Martins \& Galileo, 1990; 5, Trestonia forticornis Buquet, 1859; macho, comprimento 19,0 mm; 6, Oncideres minuta Thomson, 1868, macho, comprimento 11,0 mm.

minuta Thomson, 1868, mas difere pelos lados do metasterno cobertos por pubescência predominantemente alaranjada; pelo tegumento corporal castanho-escuro; pelas manchas brancas dos élitros mais numerosas e entremeadas por inúmeros pincéis brancos. Em O. minuta (Fig. 6), a mancha dos lados do metasterno é branca; o tegumento corporal é castanhoalaranjado e os élitros tem apenas manchas de pubescência branca com, escassos pincéis, só concentrados perto dos ápices.
Agradecimentos. A James Wappes (ACMB) pelo empréstimo do material e a Rafael Santos de Araujo, Museu de Ciências Naturais, Fundação Zoobotânica do Rio Grande do Sul, Porto Alegre, pelas execução das fotografias.

\section{REFERÊNCIAS}

Dillon, L. S. \& E. S. Dillon. 1945. The tribe Onciderini (Coleoptera: Cerambycidae). Part I. Reading Public Museum and Art Gallery, Scientific Publicatios, Reading, 5: I-XV, 1-186.

Dillon, L. S. \& E. S. Dillon. 1946. The tribe Onciderini (Coleoptera: Cerambycidae). Part II. Reading Public Museum and Art Gallery, Scientific Publicatios, Reading, 6: 189-413. 